\title{
Conscience and Compromise: Abortion and the Requirements of Justice in Medical Schools
}

\author{
Kevin Belgrave*, BA
}

\section{CORE CURRICULUM COURSES: A WORK- ABLE COMPROMISE?}

There is general agreement that no physician, medical student or resident should be forced to perform or even observe an abortion against her will (1). Furthermore, consonant with the Canadian Medical Association's clearly articulated policy on the subject, it is equally understood, at least in theory, that such a physician or student should be shown no discrimination as a result of her bona fide religious or consciencebased objection (2). Short of actually requiring students to perform or observe an abortion, however, should its methods and procedures form part of the core curriculum of Canada's medical schools? Should a medical student be required to know in detail these methods and procedures and be graded on her knowledge? The answer to these questions seems less certain. If a medical student has the well-established right, even obligation - on the grounds of conscience or religion - to object to performing or observing an abortion, does this same right allow her to object to mandatory theoretical training in the procedure? In such a "theoretical training only" situation, we seem to have the best of both worlds - a workable compromise. On the one hand, those students who have no objection to abortion are given the opportunity and, in a way, the encouragement, to learn its methods, while on the other hand, those students who object need not progress past the general education offered in a classroom setting.

\section{CORE CURRICULUM COURSES AND DISCRIMINATION}

Remaining within the useful but ultimately limited framework of "legal rights", let us examine this solution

* To whom correspondence should be addressed: Kevin Belgrave, 2661 Kingston Road, Toronto, Ontario, M1M 1M3

Email: kevin.belgrave@utoronto.ca more closely. The right of a physician or medical student not to perform or observe an abortion is not arbitrary. It is grounded ultimately in beliefs about the nature of the human person and proximately in the concepts that flow from this: justice, autonomy etc. Positive expression of this right is given in the Canadian Charter of Rights and Freedoms which protects the fundamental freedom of religion and conscience (3). Why is this relevant to evaluating the question at hand? Because at no time is the allowable content of one's freedom of religion and conscience defined by the Charter. In other words, there is no list that details the instances where one is legitimately able to exercise their right to object. The test for a valid objection is ultimately in the subject herself and not the object of her belief. Furthermore, even when an argument can be made that a certain required action is "part of the job", this cannot, in and of itself, trump an appeal to conscientious objection. For what may, on the surface, appear as a fair compromise to one person, may still run contrary to another's deeply held beliefs and convictions. Even a cursory attempt to understand the reason behind a student's objection to abortion would reveal the grave difficulty of an obligation to learn and be examined on her knowledge of what she considers to be a morally tragic reality. To illustrate this point, consider for a moment the theoretical situation faced by medical students in a country where physicians are required to facilitate the death penalty through lethal injection or otherwise. Like abortion, there is a range of opinion about the morality of capital punishment. Like abortion, capital punishment is legal in some countries and illegal in others. In countries which allow capital punishment, physicians who conscientiously object would not be ethically obliged to co-operate in the execution of prisoners. One can understand why these same physicians could not accept the "compromise" 
solution of freedom from directly facilitating execution, on the one hand, but a requirement to learn and be examined on its techniques, on the other.

\section{ADVERSE EFFECT DISCRIMINATION}

The legal concept of Adverse Effect Discrimination can help us appreciate how both the Canadian Supreme Court and provincial human rights commissions have evaluated situations analogous to the one under consideration here. Adverse Effect Discrimination occurs when some uniform practice or standard in an organisation, however honestly implemented, has a negative or "adverse" effect on a member of that organisation (4). The adverse effect results from the failure to accommodate some defined characteristic of the person when such accommodation would not involve undue hardship or sacrificing the legitimate objectives of the organisation. This principle was applied in a British Columbia human rights case in 1985 (5). Social worker Cecilia Moore was fired for refusing to sign a cheque that would release funds for a client's abortion. Despite the Ministry of Social Services' argument that such a task was "part of the job" and "related to the health of women using social services", Cecilia Moore won her case. No attempt had been made by the Ministry to accommodate her bona fide conscientious objection. Moore's supervisor had even implied that signing the authorisation would not really involve her in abortion because Moore, herself, was neither making the decision nor performing the abortion (6). This argument also failed to convince the British Columbia Council of Human Rights.

Though not an employment setting for the students, the principles at work in the Cecilia Moore case can be applied to the provision of abortion training in medical schools. In a matter as grave and highly-charged as abortion, a heavy burden rests on advocates of core curriculum change to show why a student should be required to learn the methods and procedures of abortion when her legitimately held view can be accommodated without undue hardship. Arguing that the "legitimate objectives" of medicine would be compromised as abortion is a good and necessary part of comprehensive care to women is not enough. This is far from a universally held belief. An October 2003 Leger Marketing Poll showed that $63 \%$ of Canadians believed that some measure of legal protection should be extended to human life before birth (7). This is not an insignificant number.

To mandate abortion training in medical schools would deliberately create a situation that discriminates against a significant body of students. This is neither just, nor does it respect the autonomy of the objecting student. Both legal precedent and respect for the legitimate freedom of the students and faculty argue against offering abortion training in the core curriculum of medical school.

\section{ELECTIVE OFFERINGS: A TRUE COMPROMISE?}

A second "compromise" presents itself: what about elective course offerings in abortion? In the case of elective offerings, accommodation is made for students who refuse to learn the methods and procedures of abortion. Two issues immediately present themselves, however. First, given the competitive environment of medical school and the personal and emotional dimension of many people's beliefs on abortion, including medical school faculty and students, one would be creating a situation with a possibility of discrimination. Unless there can be a high degree of certainty that no discrimination will be shown to students once their unwillingness to take abortion electives is made known, how is a school to prevent creating an environment of anxiety, fear and potential hostility among faculty and students?

Second, and more importantly, what reason is there to add such courses? The very posing of this question may rouse a certain spontaneous indignation, but honest reflection shows that the answer is not clear. One could argue that failure to make such courses available to willing students compromises their ability to provide quality and comprehensive medical care to women (8). This statement in itself is fair, but it makes the definite and clear assumption that abortion is indeed a good and necessary part of women's reproductive health care. While courts have determined that considerations of autonomy justify elective abortion, it has not been demonstrated - aside from the rare situation in which the life of the mother is endangered by the continuation of the pregnancy (9) - that abortion is ever a medically necessary procedure. In fact, in an October 2001 submission to the Canadian House of Commons Finance Committee, Canadian Abortion Rights Action League Executive Director Marilyn Wilson admitted that women who seek abortion "do so for socioeconomic reasons." (10) She continues:

\footnotetext{
Sometimes it is a desire to complete their education and become financially independent. In many cases, couples with children wish to restrict their family size in order to provide adequate financial support. Often, choosing abortion is a conscious decision not to become a socio-economic burden on society (10).
}

In the United States, the research arm of Planned Parenthood offered a similar view in its 2003 fact sheet on abortion: 
On average, women give at least 3 reasons for choosing abortion: $3 / 4$ say that having a baby would interfere with work, school or other responsibilities; about 2/3 say they cannot afford a child; and

$1 / 2$ say they do not want to be a single parent or are having problems with their husband or partner (11).

At best, these facts seriously call into question the assumption that abortion is a necessary part of reproductive health. There are many truly valuable topics related to "quality and comprehensive" reproductive health that could be offered to medical students: examples include neo-natal hospice, fertility awareness methods (both single and multi-marker methods), ovulation kits based on urine and saliva, and targeted hormone replacement. What motivation is there to insist on one particular surgical or chemical procedure to the exclusion of other relevant interventions that might benefit the reproductive health and options of women? An honest evaluation of this question will again place a real burden of proof on those advocating curriculum change. Why is it necessary, over and above what is already taught in medical schools, to make available the methods and procedures of abortion? Medical students are already taught about reproductive options, their indications and sequelae.

\section{CONCLUSION}

The concerns of students opposed to abortion go well beyond simple personal preference, opinion, or even political leaning. Opposition to abortion rests firmly in the realm of one's most fundamental beliefs and convictions about human life, human dignity and human rights. Together with this fact is the freedom of an individual to hold and manifest such fundamental beliefs and convictions and not be discriminated against as a result. It is well known that neither physicians, medical students, nor residents could ever be compelled to perform or observe abortions against their will. In this article, however, we have considered the closely related question: is it possible to require medical students to learn in detail the methods and procedures of a medical act that conflicts with their most fundamental beliefs and convictions? The answer has to be no. So long as the bona fide beliefs of an individual - explicitly grounded in conscience or religion - can be reasonably accommodated, they must be. We must respect this basic requirement of freedom in our community. Given the nature of the belief that underlies objection to abortion, it is not difficult to see how thin would be the line between performing an abortion and learning the procedure in all the detail required of a physician.

On the surface, elective course offerings appear to solve the problematic human rights question of mandatory training; however, they raise further issues that call into question the motivation behind such offerings. With strong evidence coming from the abortion advocacy community arguing against the medical necessity of abortion, and with Canadians divided on the protection that should be offered to prenatal human beings, there is little to recommend these courses. In the end, no legal reason may prevent medical schools from offering elective courses on abortion in the future; however, great care should be taken to evaluate the motives of any decision that may affect the education of future physicians, lest we do a great disservice to medical students, faculty, and mothers seeking genuine options for the care of their reproductive health.

\section{REFERENCES}

1. "A physician should not be compelled to participate in the termination of a pregnancy." Canadian Medical Association. Policy statement. Induced Abortion. Ottawa: Dec 15, 1988.

2. "No discrimination should be directed against doctors who do not perform or assist at induced abortions." Ibid.

3. Canadian Charter of Rights and Freedoms, Section 2.

4. Ontario (Human Rights Comm.) and O'Malley v. SimpsonsSears Ltd. Supreme Court of Canada. Canadian Human Rights Reporter, Vol 7. D/3102, Paragraph 24772 (1985).

5. Moore v. British Columbia (Ministry of Social Services). British Columbia Council of Human Rights. Canadian Human Rights Reporter, Vol. 17. D426 (1992).

6. Summary of the Evidence of Cecilia Moore. Submitted to the British Columbia Council of Human Rights, 1991, Parag. 38.

7. Leger Marketing National Omnibus Survey. Canadians' Opinions on Abortion. \#10598-002, 1505 Respondents $+2.5 \%$ 19 times out of 20, October 2003.

8. This is the principal argument of curriculum change advocates Medical Students for Choice. Medical Students for Choice. Curriculum Reform. Available at: http://www.ms4c.org/ issuereform.htm. Accessibility verified May 17, 2005.

9. A 1988 Planned Parenthood study numbered the percentage of abortions done for women's "health problems" at 3\%. See: Forrest J, Torres A. Why Do Women Have Abortions? Family Planning Perspectives; 1988, 24(4): 169-176.

In addition, Dr. Warren Hern, in his medical textbook Abortion Practice, notes: "A study of motivations for abortion has found that the majority are sought for socio-economic reasons." Hern W. Abortion Practice. Philadelphia: J.B. Lippincott; 1990.

10. Canada. Official Opposition Finance Critic. News Release. CARAL Admits that Abortion Done for Socio-economic Reasons. Ottawa: October 31, 2001.

11. The Alan Guttmacher Institute. Facts in Brief. Induced Abortion. New York: January 2003

Kevin Belgrave holds a Bachelor of Fine Arts from Ryerson University in Toronto and is currently enrolled in the Master of Divinity program through the Toronto School of Theology at the University of Toronto. He is the past director of the National Campus Life Network, a network of Canadian university pro-life students. 